\title{
InSb high-speed photodetectors grown on GaAs substrate
}

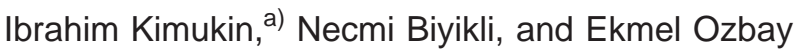 \\ Department of Physics, Bilkent University, Bilkent Ankara 06533, Turkey
}

(Received 10 March 2003; accepted 28 July 2003)

\begin{abstract}
We report InSb-based high-speed photodetectors grown on GaAs substrate. The $p-i-n$ type photodetectors can operate at room temperature. Room-temperature dark current was $4 \mathrm{~mA}$ at $1 \mathrm{~V}$ reverse bias, and the differential resistance at zero bias was $65 \Omega$. At liquid nitrogen temperature, the dark current was $41 \mu \mathrm{A}$ at $1 \mathrm{~V}$ reverse bias and the differential resistance at zero bias was $150 \mathrm{k} \Omega$. Responsivity measurements were performed at $1.55 \mu \mathrm{m}$ wavelength at room temperature. The responsivity increased with applied bias. At $0.6 \mathrm{~V}$, responsivity was $1.3 \mathrm{~A} / \mathrm{W}$, where unity quantum efficiency was observed with internal gain. Time-based high-speed measurements were performed using a pulsed laser operating at $1.55 \mu \mathrm{m}$. The detectors showed electrical responses with $40 \mathrm{ps}$ full width at half maximum, corresponding to a $3 \mathrm{~dB}$ bandwidth of $7.5 \mathrm{GHz}$. (c) 2003 American Institute of Physics. [DOI: 10.1063/1.1611286]
\end{abstract}

InSb has been an interesting material for optical applications in the infrared region due to its narrow band-gap nature. InSb can be used in infrared imaging systems, free space communication, and gas detection systems. ${ }^{1,2}$ Although InSb based photodetectors can be grown on InSb substrates ${ }^{3-5}$ this is not preferred due to high conductivity of the substrate that complicates the integration. Si and GaAs substrates are quite suitable for the monolithic integration. But due to the large lattice mismatch between InSb and $\mathrm{Si}(19 \%)$ or $\operatorname{GaAs}(14.5 \%)$, there are few reported studies. ${ }^{6-8}$ These detectors are mostly used for mid-infrared $(3-5 \mu \mathrm{m}$ wavelength) imaging applications and operate at $77 \mathrm{~K}$. Ternary compounds of $\mathrm{InSb}$ are made by adding either $\mathrm{Tl}, \mathrm{Bi}$, or As to extend the responsivity of the detectors to long wavelength infrared region. ${ }^{3,9-12}$ Although responsivity, currentvoltage, detectivity of InSb, and InSb-based photodetectors have been studied extensively, high-speed response of these infrared photodetectors have not been reported before. We report the high-speed operation of InSb photodetectors at room temperature. The electrical properties at both room and liquid nitrogen temperatures and room temperature responsivity characteristics are also reported.

The detector structure was grown on semi-insulating GaAs substrate by molecular beam epitaxy. A $0.1 \mu \mathrm{m}$ thick $\mathrm{GaSb}$ layer was grown as a buffer between lattice mismatched $\mathrm{GaAs}$ and InSb layers. InSb growth conditions and the thickness of the buffer layer were controlled using reflection high energy electron diffraction. After the buffer layer a $1.5 \mu \mathrm{m}$ thick $n^{+}$InSb layer, $1.5 \mu \mathrm{m}$ thick $n$-InSb layer, and finally $0.5 \mu \mathrm{m}$ thick $p^{+}$InSb layer were grown. The $n$-active layer was unintentionally doped to $2 \times 10^{15} \mathrm{~cm}^{-3}$. Tellurium and beryllium were used as the $n$ - and $p$-layer dopants, respectively. Doping level was $10^{18} \mathrm{~cm}^{-3}$ for both highly doped layers to decrease the serial resistance. The thickness of the top $p^{+}$layer was kept lower than the $n^{+}$layer to increase the quantum efficiency.

\footnotetext{
a) Author to whom correspondence should be addressed; electronic mail: kimukin@fen.bilkent.edu.tr
}

The devices were fabricated by a microwave-compatible process and completed in five steps. Citric acid: $\mathrm{H}_{2} \mathrm{O}_{2}(1: 1)$ solution was used to etch the InSb and GaSb layers. Solution was kept at $30^{\circ} \mathrm{C}$ and stirred to get a uniform etch profile. This was an isotropic etch with an etch rate of $\sim 1.5 \mu \mathrm{m} / \mathrm{h}$. We started the fabrication with the $n^{+}$ohmic contact formation. Samples were etched down to the $n^{+}$InSb layer, which was followed by a self-aligned Ti-Au liftoff. The $p^{+}$ohmic contact was also achieved by Ti-Au liftoff. We etched away all the layers down to semi-insulating GaAs, except for the active areas using the isolation mask. Then $0.19 \mu \mathrm{m} \mathrm{Si}_{3} \mathrm{~N}_{4}$ layer was covered and patterned for isolation and passivation. This dielectric layer was also used as a single layer antireflection coating. Finally a $0.8 \mu \mathrm{m}$ thick $\mathrm{Ti}-\mathrm{Au}$ metal was evaporated, which formed the coplanar waveguide on the top of the GaAs layer, which was essential for high-speed operation. ${ }^{13,14}$ We fabricated photodetectors with different active areas changing from 30 to $200 \mu \mathrm{m}$ in diameter.

Current-voltage characteristics of the detectors were measured at room and liquid nitrogen temperature using a modular dc source/monitor unit (HP-4142B). Figure 1 shows the current-voltage characteristics of a detector with $30 \mu \mathrm{m}$ diameter. At room temperature dark current was $6.4 \mu \mathrm{A}$ at zero bias and $4 \mathrm{~mA}$ at $1 \mathrm{~V}$ reverse bias. At $77 \mathrm{~K}$, the dark current was $20 \mathrm{nA}$ at zero bias and $41 \mu \mathrm{A}$ at $1 \mathrm{~V}$ reverse bias. The inset of Fig. 1 shows the calculated differential resistance of the photodetector. At room temperature differential resistance was $65 \Omega$ at zero bias, and the highest value was $650 \Omega$ at $440 \mathrm{mV}$ reverse bias. The peak position of the differential resistance shifted to higher bias voltages as the temperature was lowered. ${ }^{7}$ When the diode was cooled to 77 $\mathrm{K}$, the differential resistance at zero bias was $150 \mathrm{k} \Omega$ and the highest value was $170 \mathrm{k} \Omega$ at $40 \mathrm{mV}$ forward bias. Zero-bias differential resistance area product $\left(R_{0} A\right)$ for $30 \mu \mathrm{m}$ diam diodes was $1 \Omega \mathrm{cm}^{2}$. This product increased to $2 \Omega \mathrm{cm}^{2}$ for $80 \mu \mathrm{m}$ diam diodes. Our values were comparable to the reported $R_{0} A$ values. The $R_{0} A$ for InSb photodetectors grown on $\mathrm{Si}$ were $1 \Omega \mathrm{cm}^{2}\left(400 \times 400 \mu \mathrm{m}^{2}\right.$ area) and $2.6 \Omega \mathrm{cm}^{2}$ $\left(400 \times 80 \mu \mathrm{m}^{2}\right.$ area). ${ }^{7,8} R_{0} A$ was $0.5 \Omega \mathrm{cm}^{2}$ for $50 \times 200 \mu \mathrm{m}^{2}$ 


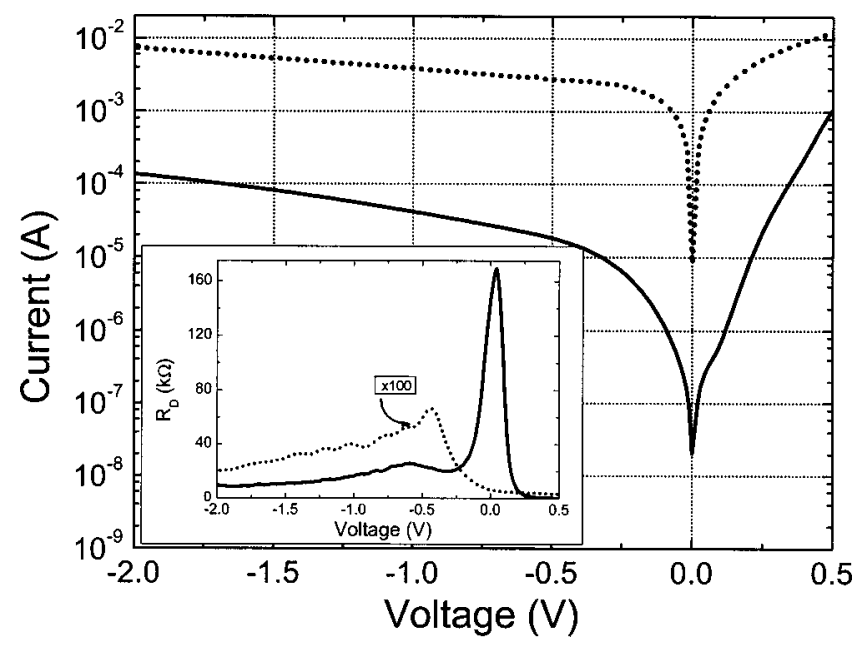

FIG. 1. Electrical characteristics of a PIN $30 \mu \mathrm{m}$ diam InSb photodetector measured at room temperature (dotted line) and $77 \mathrm{~K}$ (solid line). The inset shows the calculated differential resistance.

area InAsSb photodetector grown on GaAs. ${ }^{10}$

Spectral responsivity measurements were made using a tunable laser at room temperature. The output of the laser was coupled to a single-mode fiber and delivered to the active area of the photodetector using a fiber probe. The photocurrent was recorded by digital ammeter while the detectors were biased using a dc voltage source. First the responsivity of the photodetectors at $1550 \mathrm{~nm}$ was measured as a function of bias voltage. The responsivity increased with the increase of the reverse bias as shown in Fig. 2. Under 0.2 $\mathrm{V}$ reverse bias the responsivity was $0.58 \mathrm{~A} / \mathrm{W}$, which corresponds to $46 \%$ quantum efficiency $(\mathrm{QE})$. Due to the internal gain, the QE exceeded unity with the increase of the reverse bias above $0.6 \mathrm{~V}$. Spectral responsivity measurements were made in the $1500-1600 \mathrm{~nm}$ spectral range which were also shown at the inset of Fig. 2. The photoresponse was nearly constant in the given range. This was also in agreement with the spectral absorption simulations based on the transfer matrix method. Figure 3 shows the simulation results of reflec-

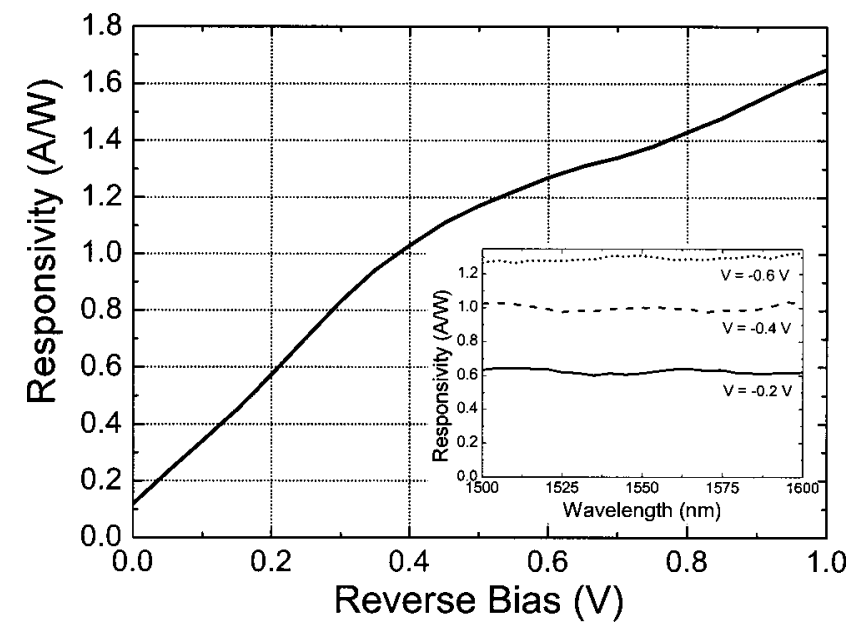

FIG. 2. Responsivity of the photodetectors at $1550 \mathrm{~nm}$ as a function of the reverse bias. The inset shows the spectral responsivity measurement under different reverse bias voltages ranging from 0.2 to $0.6 \mathrm{~V}$.

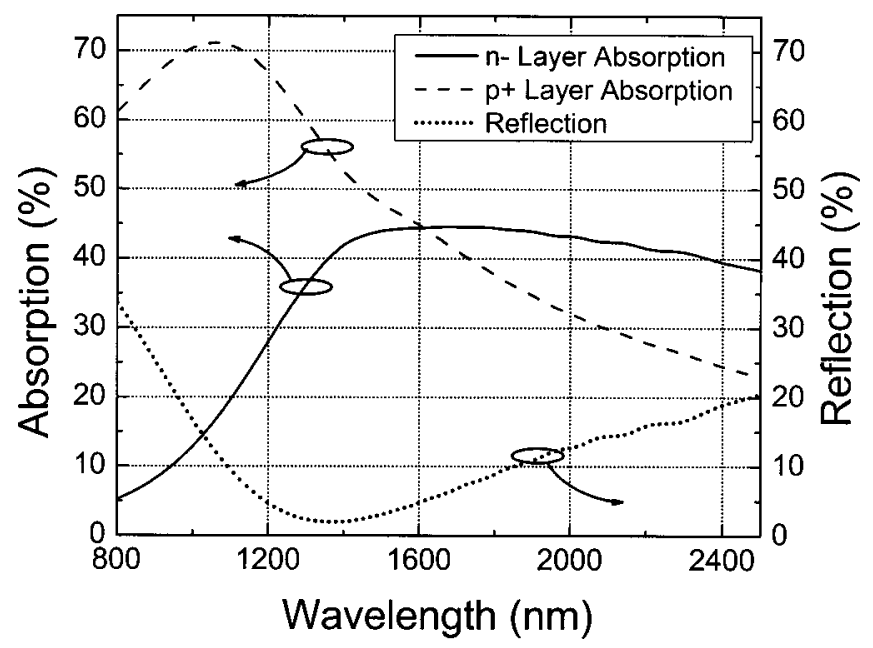

FIG. 3. Spectral simulation results for optical reflection and absorption in the $p^{+}$and $n$-InSb layers.

tion and absorption for the fabricated detector. Below 1400 $\mathrm{nm}$, most of the optical signal was absorbed in the upper $p^{+}$ InSb layer due to high absorption coefficient. ${ }^{15,16}$ Between 1400 and $2000 \mathrm{~nm}$, the absorption in the $n$ layer was nearly constant. Simulations show that a further increase in the QE can be achieved by using a thinner $p^{+}$layer and by tuning the antireflection coating to the desired wavelength.

High-speed characterization of the photodetectors was carried out at $1550 \mathrm{~nm}$. An erbium doped fiber laser amplifier was used to generate optical pulses with a full width at half maximum (FWHM) of 1 ps. Optical pulses from the laser were coupled to the active area of the photodiodes by means of a fiber probe. The detectors were biased using a $40 \mathrm{GHz}$ bias tee on a microwave probe station. The temporal response of the photodetectors were measured on a $50 \mathrm{GHz}$ sampling scope. ${ }^{17}$ Under zero bias the pulse was very wide. As the reverse bias was increased above $1.0 \mathrm{~V}$, the peak increases to $200 \mathrm{mV}$ and the FWHM decreased to $45 \mathrm{ps}$. The pulse response of a $30 \mu \mathrm{m}$ diam photodetector measured under 2.0 V reverse bias is shown in Fig. 4. The shape of the pulse response was almost the same above $1.5 \mathrm{~V}$ reverse

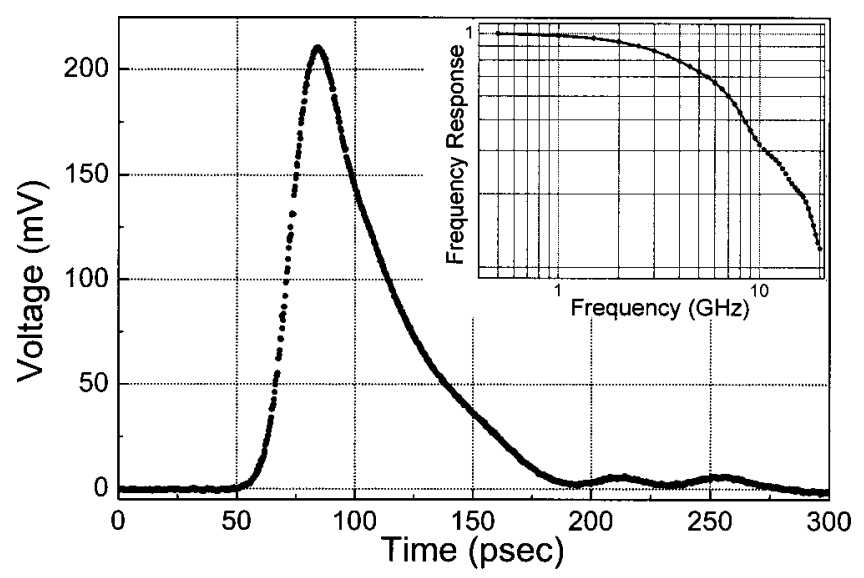

FIG. 4. Temporal response of a $30 \mu \mathrm{m}$ PIN InSb photodetector measured at $2 \mathrm{~V}$ reverse bias. The inset shows the calculated FFT of this measurement where the $3 \mathrm{~dB}$ bandwidth is $7.5 \mathrm{GHz}$. 
bias. The pulse had a 40 ps FWHM without any ringing. The rise time was 15 ps and the fall time was 73 ps. The tail was due to the diffusion of the carriers generated in the highly doped layers to the active layer. The fast fourier transform of the pulse is shown in the inset of Fig. 4, which shows that the device has a $3 \mathrm{~dB}$ bandwidth of $7.5 \mathrm{GHz}$.

In conclusion, we have demonstrated the high-speed operation of InSb-based photodetectors. Room temperature and liquid nitrogen temperature zero bias differential resistances were $65 \Omega$ and $150 \mathrm{k} \Omega$, respectively. Responsivity at 1.55 $\mu \mathrm{m}$ wavelength was $1.3 \mathrm{~A} / \mathrm{W}$ at $0.6 \mathrm{~V}$ reverse bias. The detectors showed electrical responses with 40 ps FWHM, corresponding to a $3 \mathrm{~dB}$ bandwidth of $7.5 \mathrm{GHz}$.

This work was supported by Turkish Department of Defense Grant No. KOBRA-002 and NATO Grant No. SfP971970.

${ }^{1}$ C. E. Volin, J. P. Garcia, E. L. Dereniak, M. R. Descour, T. Hamilton, and R. McMillan, Appl. Opt. 40, 4501 (2001).

${ }^{2}$ B. J. Kirby and R. K. Hanson, Appl. Opt. 41, 1190 (2002).

${ }^{3}$ S. R. Kurtz, L. R. Dawson, T. H. Zipperian, and R. D. Whaley, Jr., IEEE Electron Device Lett. 11, 54 (1990).

${ }^{4}$ T. Ashley, A. B. Dean, C. T. Elliott, C. F. McConville, and C. R.
Whitehouse, Electron. Lett. 24, 1270 (1988).

${ }^{5}$ I. Bloom and Y. Nemirovsky, IEEE Trans. Electron Devices 40, 309 (1993).

${ }^{6}$ W. Dobbelaere, J. De Boeck, P. Heremans, R. Mertens, G. Borghs, W. Luyten, and J. Van Landuyt, Appl. Phys. Lett. 60, 3256 (1992).

${ }^{7}$ E. Michel, J. Xu, J. D. Kim, I. Ferguson, and M. Razeghi, IEEE Photonics Technol. Lett. 8, 673 (1996).

${ }^{8}$ A. Tevke, C. Besikci, C. V. Hoof, and G. Borghs, Solid-State Electron. 42, 1039 (1998).

${ }^{9}$ J. D. Kim, S. Kim, D. Wu, J. Wojkowski, J. Xu, J. Piotrawski, E. Bigan, and M. Razeghi, Appl. Phys. Lett. 67, 2645 (1995).

${ }^{10}$ C. Besikci, S. Ozer, C. V. Hoof, L. Zimmerman, J. John, and P. Merken, Semicond. Sci. Technol. 16, 992 (2001).

${ }^{11}$ J. G. Crowder, T. Ashley, C. T. Elliot, G. J. Pryce, and A. D. Johnson, Electron. Lett. 36, 1867 (2002).

${ }^{12}$ J. D. Kim, D. Wu, J. Wojkowski, J. Piotrowski, J. Xu, and M. Razeghi, Appl. Phys. Lett. 68, 99 (1996).

${ }^{13}$ I. Kimukin, E. Ozbay, N. Biyikli, T. Kartaloglu, O. Aytür, S. Ünlü, and G. Tuttle, Appl. Phys. Lett. 77, 3890 (2000).

${ }^{14}$ N. Biyikli, I. Kimukin, O. Aytür, M. Gokkavas, S. Ünlü, and E. Ozbay, IEEE Photonics Technol. Lett. 13, 705 (2001).

${ }^{15}$ E. D. Palik, Handbook of Optical Constants of Solids (Academic, Orlando, FL, 1998), Vol. 1.

${ }^{16}$ T. S. Moss, in Semiconductors and Semimetals, edited by R. K. Willardson and A. C. Beer (Academic, New York, 1966), Vol. 2.

${ }^{17}$ I. Kimukin, N. Biyikli, B. Butun, O. Aytur, S. Ünlü, and E. Ozbay, IEEE Photonics Technol. Lett. 14, 366 (2002). 